\title{
The new Genetico-Racial Skin Classification: How to maximize the safety of any peel or laser treatment on any Asian, Caucasian or Black patient
}

\author{
Nabil Fanous MD FRCSC ${ }^{1,2,3}$, Valérie Côté MD $^{1}$, Amanda Fanous ${ }^{4}$
}

N Fanous, V Côté, A Fanous. The new Genetico-Racial Skin Classification: How to maximize the safety of any peel or laser treatment on any Asian, Caucasian or Black patient. Can J Plast Surg 2011;19(1):9-16.

The popular skin classifications, notably the 'Fitzpatrick' and 'Obaji' classifications, are primarily based on skin colour. Other criteria are occasionally considered, such as the degree of skin oiliness, thickness, sensibility, etc. Although these classifications are easy to understand and apply, their simplicity limits their precision, sophistication and applicability.

The new genetico-racial skin classification proposed herein suggests that skin response to any peel or laser treatment is genetically programmed and is, therefore, linked to the genetic and racial origin of the patient. In other words, in addition to skin colour, the patient's facial features and ancestry should be taken into account when classifying any skin.

The new genetico-racial skin classification enables the physician to determine with great precision, and before any peel or laser treatment, the level of the patient's suitability and the expected postoperative outcomes; therefore, reducing the likelihood of complications.

Key Words: Classification; Genetics; Laser; Peel; Racial; Skin
La classification généticoraciale de la peau : Comment porter au maximum la sécurité d'un traitement de peeling chimique ou au laser chez un patient asiatique, blanc ou noir

Les classifications cutanées populaires, notamment les classifications de « Fitzpatrick » et d' "Obaji », se fondent principalement sur la couleur de la peau. D'autres critères sont parfois envisagés, tels que le degré d'huile de la peau, son épaisseur, sa sensibilité, etc. Ces classifications sont faciles à comprendre et à appliquer, mais leur simplicité limite leur précision, leur subtilité et leur applicabilité. Selon la nouvelle classification généticoraciale de la peau proposée aux présentes, la réponse de la peau à un traitement d'excoriation ou au laser est programmée génétiquement et, par conséquent, liée à l'origine génétique et raciale du patient. Autrement dit, en plus de la couleur de la peau, il faut tenir compte des caractéristiques faciales et de l'ascendance du patient pour classer la peau.

La nouvelle classification généticoraciale de la peau permet au médecin de déterminer avec grande précision, avant un traitement d'excoriation ou au laser, le taux d'acceptabilité du patient et les résultats postopératoires prévus, réduisant ainsi le risque de complications.
$\mathrm{T}$ raditional skin classifications (1-5), such as the 'Fitzpatrick' and 'Obagi' classifications, are primarily based on skin colour. The prevailing general assumption, reigning in dermatological and plastic surgery circles, is that the result of a peel, laser or dermabrasion treatment is directly related to the intensity of the skin colour: the lighter the skin, the better the result; the darker the skin, the poorer the result.

This oversimplification, although attractive at first, is inadequate for providing much needed answers to the likely response and risks of each skin category to the treatments. In fact, in certain instances, these classical classifications may be misleading and even counterproductive.

The new genetico-racial skin classification, first introduced by the senior author (6-12), suggests that taking the racial origin of the patients into consideration enables the physician to predict with precision the suitability, risks and outcome of a skin treatment before it is performed on a specific patient.

\section{THE GENETICO-RACIAL ORIGINS}

Anthropologists have traced the origins of mankind back to approximately four million years ago in Africa. Homo habilis, the first tool-maker ancestor, lived approximately two million years ago, followed by Homo erectus approximately one million years ago. Eventually, Homo sapiens evolved and wandered out of Africa to spread across Europe and Asia approximately 100,000 to 200,000 years ago. From then to now, during such a seemingly short period within a historical context, the human race differentiated into three main races over the three ancient continents: the Negroid race in Africa, the Caucasian race in Europe and the Mongoloid race in Asia.

In other words, for millions of years, our ancestors stationed in Africa shared common characteristics. However, as soon as they changed geographical habitats, and within only a few hundred thousands of years, their body traits evolved dramatically in diverging directions to adapt to their novel environments. The emerging differences in feature contours and skin colour may be explained on the basis of the Darwinian evolutionary principle of 'natural selection' (13), with the effect of preserving the individuals most adapted to survive in their new climate, while ruthlessly eliminating the unfit ones.

Therefore, over many thousands of years, nature has modified the genetic and racial characteristics of each race to suit its continent (13-17), changing the colour of the skin and the shape of the features, as well as adapting the skin reaction to the surrounding negative habitat elements such as extreme heat, extreme cold, extreme dryness, extreme humidity, abundant sun or lack of it, rain, storms, snow, etc. This genetically programmed response of skin to external environmental assaults seems to be the main determining factor in our response to other external types of assaults: peels, lasers and other skin treatments.

${ }^{1}$ Department of Otolaryngology - Head and Neck Surgery, McGill University, Montreal; ${ }^{2}$ The Department of Surgery, Sherbrooke University,

Sherbrooke; ${ }^{3}$ The Canadian Institute of Cosmetic Surgery; ${ }^{4}$ The School of Medicine, McGill University, Montreal, Quebec

Correspondence: Dr Nabil Fanous, 1 Westmount Square, Suite 1380, Montreal, Quebec H3Z 2P9. Telephone 514-935-9906,

fax 514-935-6482, e-mail cosmeticsurgery123@videotron.ca 


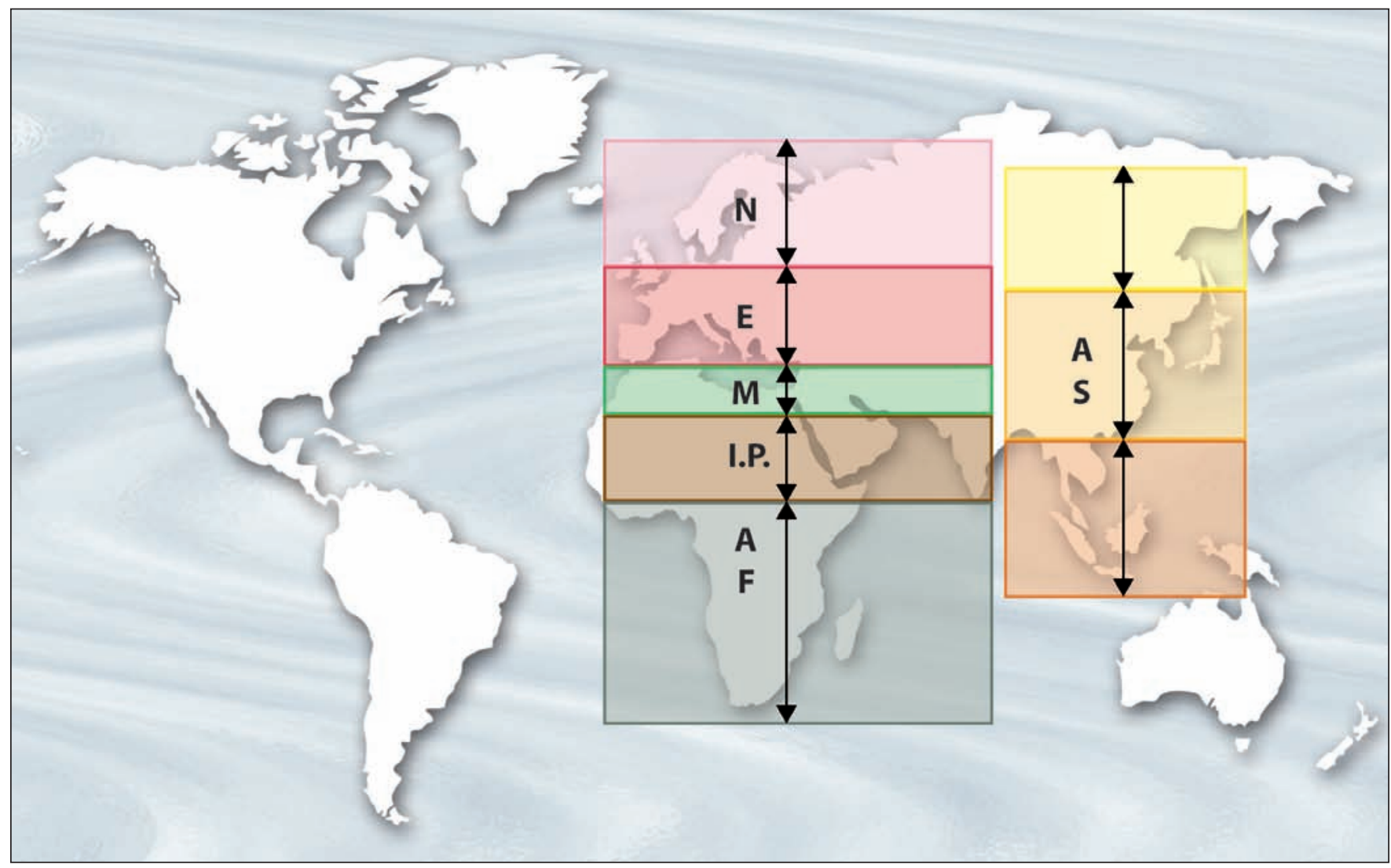

Figure 1) The new genetico-racial classification of skin colour and features runs in a north-to-south direction, vertically across Europe and Africa, and in a parallel vertical direction across Asia. In Europe and Africa, the following roots are found: N Nordic (pink), E European (red), M Mediterranean (green), I.P. Indo-Pakistani (brown), AF African (grey). In Asia, the Asian (AS) roots are found: northern Asian (yellow), central Asian (light orange) and southern Asian (dark orange)

\section{THE GENETICO-RACIAL CLASSIFICATION}

The basic theory

As previously discussed, the human race evolved into three founding races (Negroid, Caucasian and Mongoloid) inhabiting the three ancient continents (Africa, Europe and Asia). It is obvious that skin colour and facial features are very different among the three races. As well, within each continent, there are differences within the same race.

The amazing 'north to south' phenomenon

Furthermore, if we study the different races across the ancient continents of Africa, Europe and Asia, we are faced with a most startling phenomenon:

As we cross the globe from north to south, going from the coldest to the warmest climate, the skin colour and the feature characteristics change in the most predictable and calculated manner, from one extreme to another. The very white, thin skin and the very delicate facial features of the most northern populations change gradually, in successive and almost precise increments, to the very black thick skin and the coarse robust features of the most southern populations.

\section{The six genetico-racial categories}

Based on the previous phenomenon, one can easily spot the incremental changes in skin colour, skin thickness and facial characteristics among the three founding races, and even within each race. These variations are detectable from north to south, across the three ancient continents.

For practicality and simplicity, the genetico-racial classification divides the three founding races into six genetico-racial subtypes, which are encountered as we proceed from north to south (Figure 1):

\section{Across Europe and Africa}

1. The Nordics: individuals originating from northern Europe (e.g. Scandinavian, Irish or Scottish roots).

2. The Europeans: individuals originating from mid-Europe (e.g. German, English, northern Spanish, northern Italian, Polish or French roots).

3. The Mediterraneans: individuals originating from southern Europe, most northern Africa and western middle Asia (e.g. southern Italian, southern Spanish, Portuguese, Greek, Lebanese or Iranian roots).

4. The Indo-Pakistanis: individuals originating from upper-middle Africa, western lower Asia (e.g. Pakistani, Thai, Indian, Egyptian or Saudi roots).

5. The Africans: individuals originating from middle and lower Africa (e.g. Sudanese, Ethiopian or South African roots).

\section{Across central and eastern Asia}

6. The Asians: individuals originating from central and eastern Asia (e.g. Korean, Chinese, Japanese or Philippino roots).

Table 1 summarizes the characteristics of each genetico-racial category. Figures 2,3,4 and 5 show examples of individuals representing the different genetico-racial categories.

\section{Origins versus country of residence}

In all instances, patients should be classified according to their 'country of origin' rather than their 'country of residence'. In other words, the skin of an African-American is classified as 'African' even if he/she lives in Alaska. Likewise, the skin of a South African citizen, who is white with an Irish descent, is still classified as 'Nordic'. 


\begin{tabular}{|c|c|c|c|c|}
\hline \multicolumn{5}{|c|}{ Summary of the characteristics and responses of the different genetico-racial categories } \\
\hline Racial category & $\begin{array}{l}\text { Original } \\
\text { geographical habitat }\end{array}$ & $\begin{array}{l}\text { Characteristics of skin and facial } \\
\text { features }\end{array}$ & Side effects/complications & Rating as candidate \\
\hline $\begin{array}{l}\text { Mediterraneans } \\
\text { (e.g.: Spanish, Greek) }\end{array}$ & $\begin{array}{l}\text { Southern Europe, } \\
\text { most northern Africa, } \\
\text { western Asia }\end{array}$ & $\begin{array}{l}\text { Colour: medium tan } \\
\text { Skin: slightly thick } \\
\text { Features: slightly coarse } \\
\end{array}$ & $\begin{array}{l}\text { - Erythema + to ++ } \\
\text { - Hyperpigmentation + to ++ }\end{array}$ & - Very good \\
\hline $\begin{array}{l}\text { Indo-Pakistanis } \\
\text { (e.g.: Pakistani, Thai) }\end{array}$ & $\begin{array}{l}\text { Northern Africa, } \\
\text { southern Asia }\end{array}$ & $\begin{array}{l}\text { Colour: deep tan to dark brown } \\
\text { Skin: thick } \\
\text { Features: moderate to coarse } \\
\end{array}$ & $\begin{array}{l}\cdot \text { Hyperpigmentation +++ } \\
\cdot \text { Hypopigmentation }+\end{array}$ & $\begin{array}{l}\text { - Good for medium peels } \\
\text { - Passable for deep peels or } \\
\text { light laser resurfacing }\end{array}$ \\
\hline $\begin{array}{l}\text { Asians } \\
\text { (e.g.: Japanese, } \\
\text { Korean) }\end{array}$ & $\begin{array}{l}\text { Central Asia, eastern } \\
\text { Asia }\end{array}$ & $\begin{array}{l}\text { A separate classification } \\
\text { Colour: varies from light to medium to dark } \\
\text { Skin: thick to very thick } \\
\text { Features: coarse to very coarse }\end{array}$ & $\begin{array}{l}\cdot \text { Hyperpigmentation }+++ \\
\text { - Erythema }++, \text { turning to } \\
\text { hyperpigmentation }\end{array}$ & - Good \\
\hline
\end{tabular}

\section{Special genetico-racial variations}

The Aboriginals of North America: The North American Aboriginals mostly comprise the First Nations, the Inuit and the Métis (descendents of mixed marriages between First Nations and Europeans).

According to archeologists, North and South America were the last continents to become inhabited by humans. The most widely accepted theory is that, because of falling sea levels, the Asian population began migrating to North America approximately 50,000 years ago across the 'Bering Land Bridge' that joined Siberia to Alaska during the last Ice Age. This migration seemed to have continued until approximately 11,000 years ago, when the Land Bridge is believed to have ceased to exist. The new immigrants were first confined to Alaska, and only started moving south across North and South America approximately 16,000 years ago, after the glaciers melted.

The Aboriginals of Australia: Australian Aboriginals are the indigenous inhabitants of mainland Australia. These ancestors date back to between 40,000 and 100,000 years ago, probably originating from New Guinea. They are, therefore, most closely related to the southern Asians, exhibiting dark brown skin and very coarse features.

The Mullatoes: Mullatoes are individuals with mixed black and white ancestry. They are particularly well represented in Latin America, often constituting the majority of the population (e.g. $73 \%$ in the Dominican Republic, and $70 \%$ in Cuba). Most are descendents of intermarriages between European settlers and imported black African workers. Therefore, their skin and feature characteristics, as well as their classification, reflect a combination of two origins.

\section{HOW TO USE THE NEW SKIN CLASSIFICATION: A SIMPLIFIED TWO-STEP APPROACH}

Step 1: How to classify the skin of a patient

a) Examine the patient's skin colour and features: In the majority of cases, the diagnosis is obvious and takes a split second to make. For example, a black patient with African facial traits is automatically classified as 'African', regardless of where the patient lives. Similarly, a patient with obvious Asian features is classified as 'Asian' (in such a case, a light coloured skin will denote a northern Asian origin such as Siberia, while a darker skin will point to a southern Asian one such as the Philippines).
As well, a patient with very light skin, blue eyes, blond hair and delicate features can be safely classified as 'Nordic'.

b) Just ask the patient where his parents or grandparents were originally from: If the diagnosis is not obvious by simply looking at the patient, the answer to the above question will provide the proper classification. For example, if the patient has European features but darker skin than expected, and says he/she is half German and half Indian, then he/she probably fits in the Mediterranean category, between the European and the Indo-Pakistani categories. In other cases, when it is difficult to decide between two categories, one can include both (e.g. European/Mediterranean for a southern Italian who has European features and a Mediterranean skin tan).

Step 2: How to benefit from the classification Once the skin is classified, the outcome can be predicted, the treatment can be adjusted and complications can be prevented by remembering the following important points associated with each category:

Nordics (Figure $2-\mathrm{A} 1, \mathrm{~A} 2$ ) in a nutshell

- Very good candidates as long as the treatment is not aggressive.

- Because of their thin skin, deep peels or heavy lasers may lead to persistent erythema, telangiectasia or worse, scarring.

Europeans (Figure $2-\mathrm{B} 1, \mathrm{~B} 2$ ) in a nutshell

- Best candidates.

- Experience the fewest side effects and complications.

Mediterraneans (Figure $3-\mathrm{C} 1, \mathrm{C} 2$ ) in a nutshell

- Good to very good candidates.

- Develop erythema and moderate hyperpigmentation (which is almost always temporary).

Indo-Pakistanis (Figure 3 - D1, D2) in a nutshell

- Acceptable candidates only if peels are medium and lasers are light.

- Exhibit erythema and severe hyperpigmentation (which is almost always temporary).

- Because of their darker skin, they risk developing hypopigmentation (which may become permanent). 


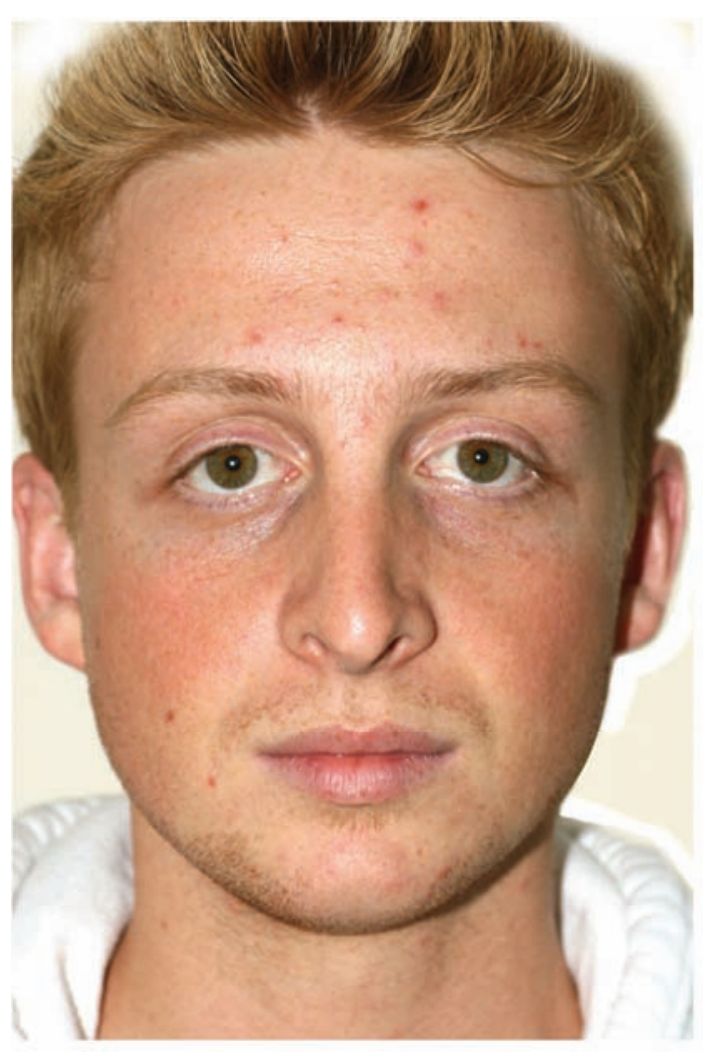

A1

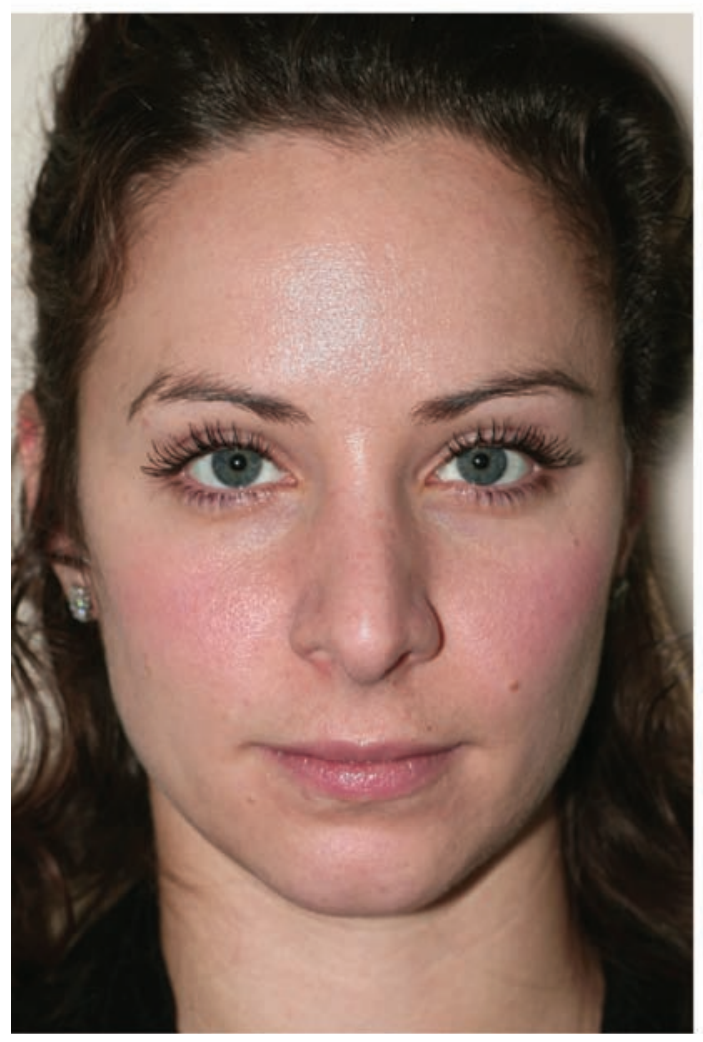

B1

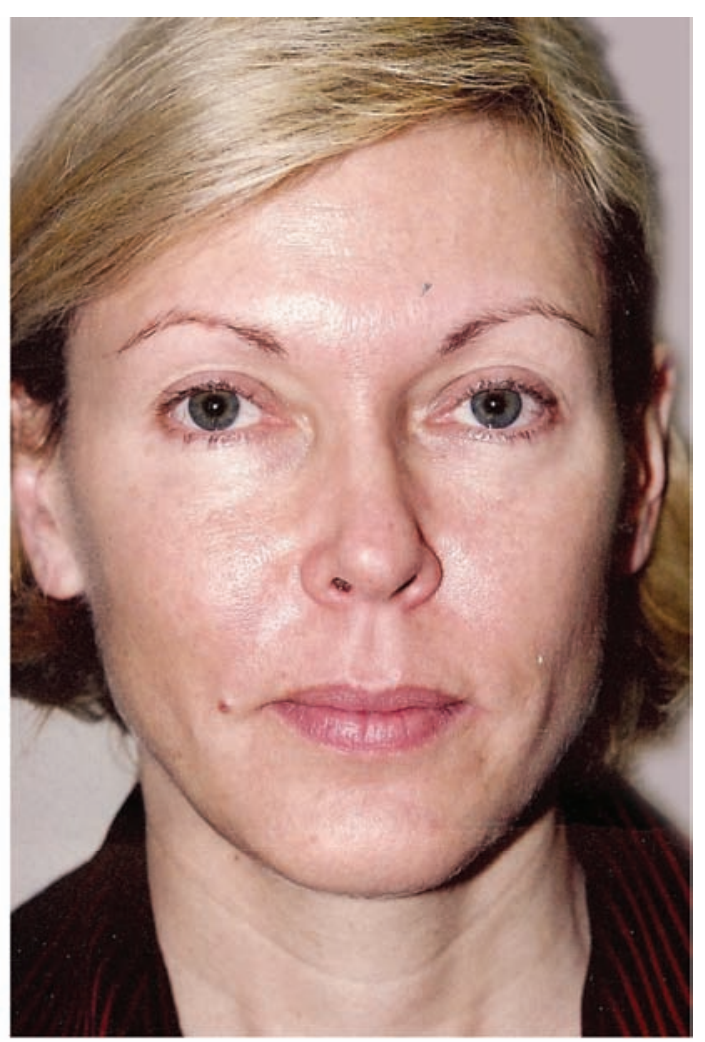

A2

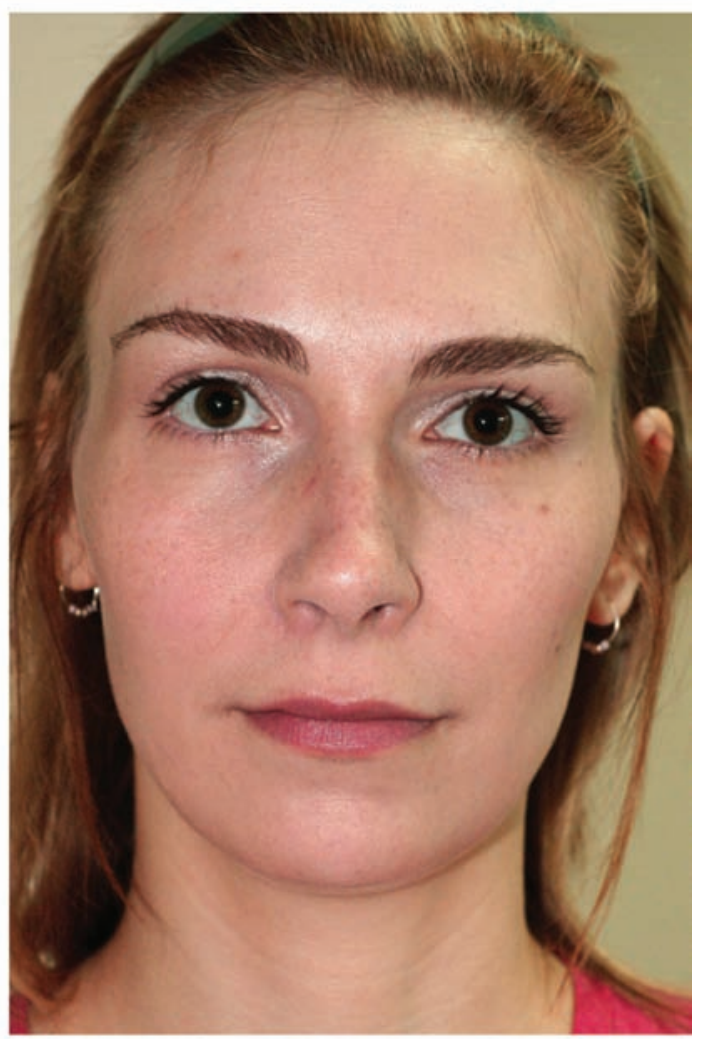

B2

Figure 2) A1, A2 - Examples of patients with Nordic roots: pale white thin skin, fine features; B1, B2 - Examples of patients with European roots: white or slightly tanned skin, medium features 


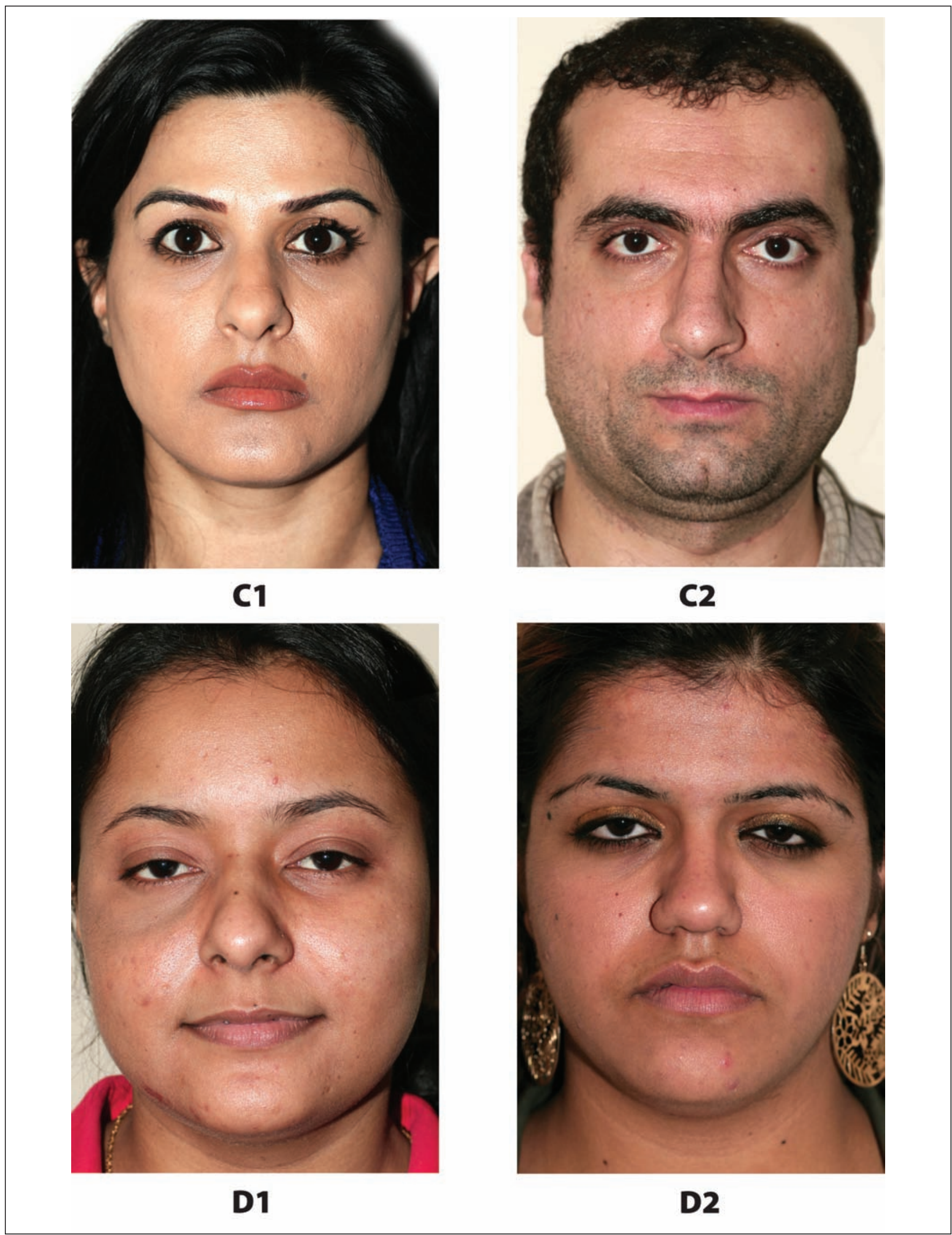

Figure 3) C1, C2 - Examples of patients with Mediterranean roots: darker tanned skin, mildly coarse features; D1, D2 - Examples of patients with Indo-Pakistani roots: medium to deep brown thick skin, moderately coarse features 


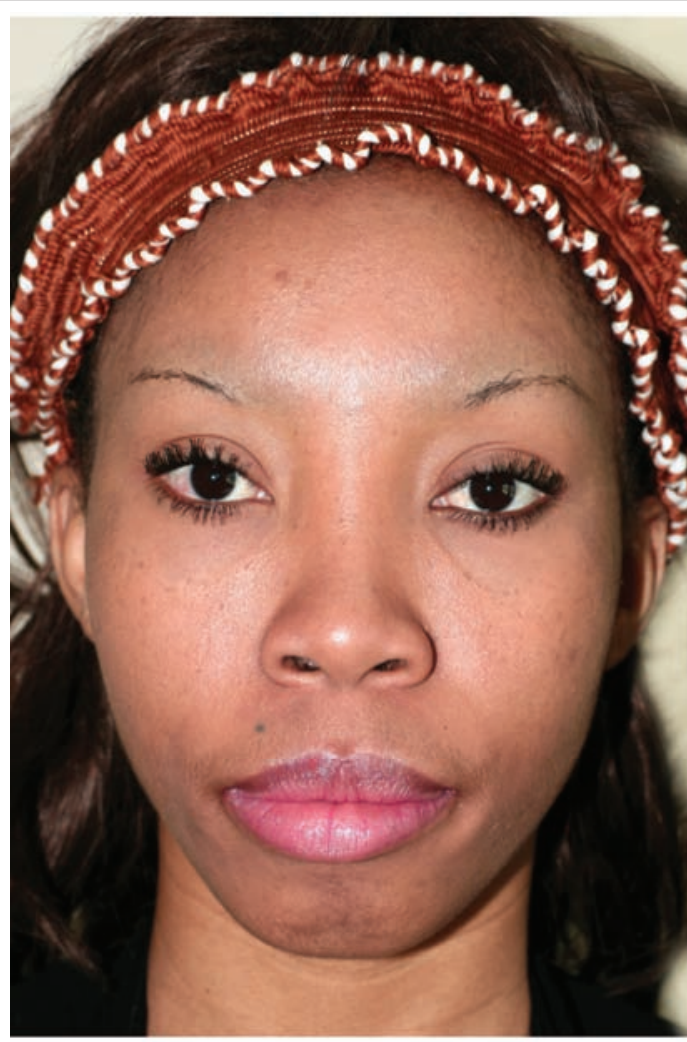

E1

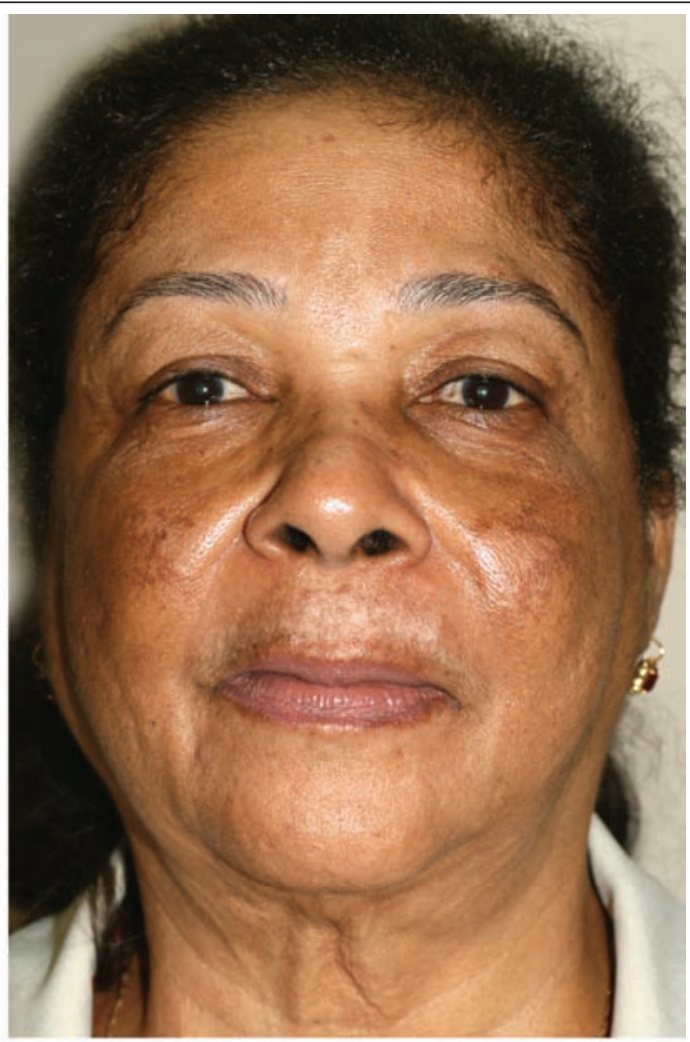

E2

Figure 4) E1, E2 - Examples of patients with African roots: black thick skin, very coarse features

Africans (Figure $4-\mathrm{E} 1, \mathrm{E} 2)$ in a nutshell

- Potentially dangerous candidates.

- Because of their black skin colour, they have a greater tendency for hypopigmentation (which is often permanent).

- Are conditionally acceptable candidates, only in expert hands, and only for 'light to medium' peels or very light lasers (they are more susceptible to lasers than to peels).

Asians (Figure $5-$ F1, F2, F3) in a nutshell

- Good candidates

- Tend to develop moderate to severe hyperpigmentation, which is almost always reversible but may take weeks or even months to resolve.

- Tend to develop variable erythema, which evolves into hyperpigmentation.

- The darker skinned southern Asian groups, in addition to erythema and hyperpigmentation, may develop hypopigmentation, which may be permanent.

Special genetico-racial variations: Aboriginals and Mullatoes

- Have unpredictable responses. However, they are conditionally acceptable candidates if treated carefully (i.e. medium peels, light lasers).

- Have a tendency to develop severe hyperpigmentation (often persisting for months), hypertrophic or keloid scarring and hypopigmentation (in patients with darker skin).

\section{CONCLUSION}

Racial genetics play a significant role in determining a patient's response to any skin treatment. Contrary to traditional skin classifications, the new genetico-racial classification takes into consideration the racial origins of patients (as manifested in both their skin colour and feature contour characteristics), rather than their skin colour alone. According to this new classification system, patients may belong to one of six categories, originating from the three ancient continents: Africa, Europe and Asia.

\section{THE NEW SKIN CLASSIFICATION IN A NUTSHELL}

The genetico-racial classification system introduces a 'paradigm shift' in the way we see skin before, during and after any peel or laser treatment:

a) Genetic programming in different races controls the patients' response to skin treatments and their susceptibility to complications.

b) Three criteria allow us to determine the patient's genetico-racial category: features, skin colour and country of origin of the patient's parents and grandparents.

c) Patients belonging to the most northern category (Nordics) and the ones belonging to the most southern categories (IndoPakistanis and Africans) are potentially dangerous candidates if not treated carefully because they are susceptible to 'irreversible' complications, mainly scarring and hypopigmentation, respectively.

d) Aboriginals and Mullatoes are potentially dangerous candidates if not treated carefully because of their unpredictable reactions to skin treatments.

ACKNOWLEDGMENTS: The authors thank Minerva Khalife for organizing the manuscript and for medical photography, Michael Fanous for the literature research, Ildiko Horvath for her assistance in preparing the artwork, Catherine Dalal for typing the manuscript and Barbara Armbruster and Stephanie Luetticken for editing. 


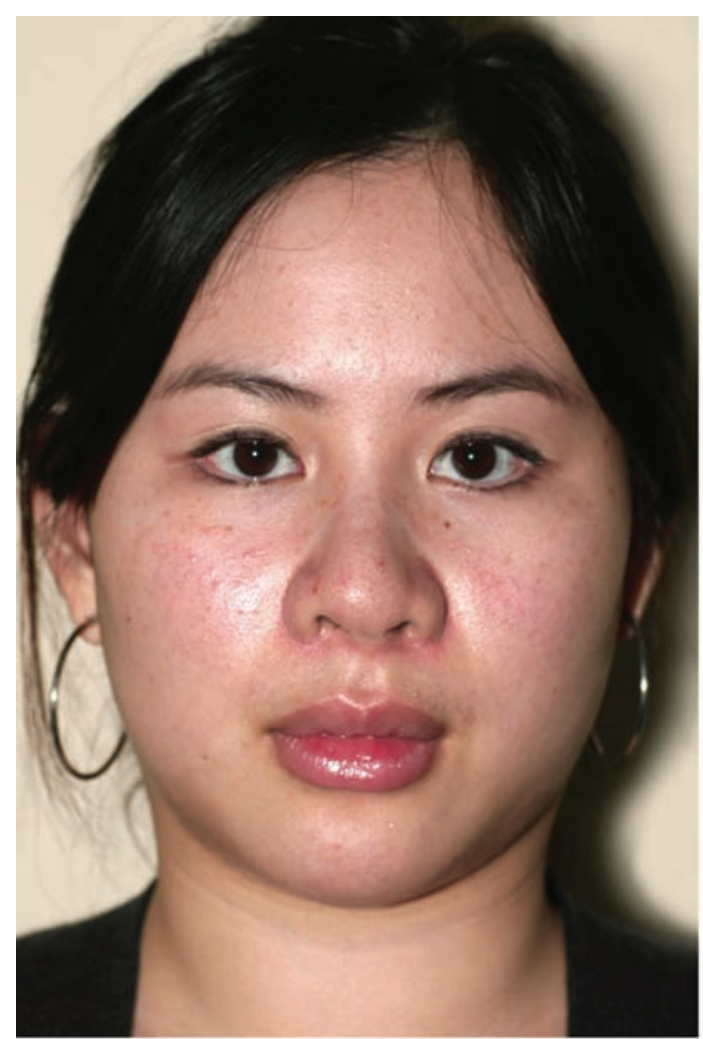

F1

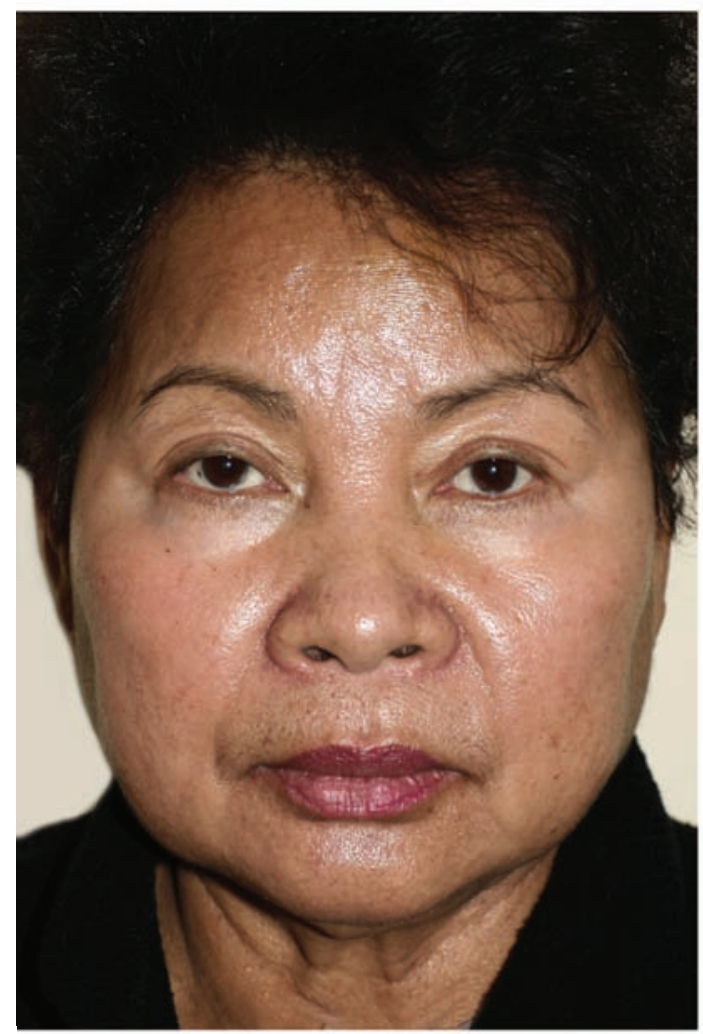

F3

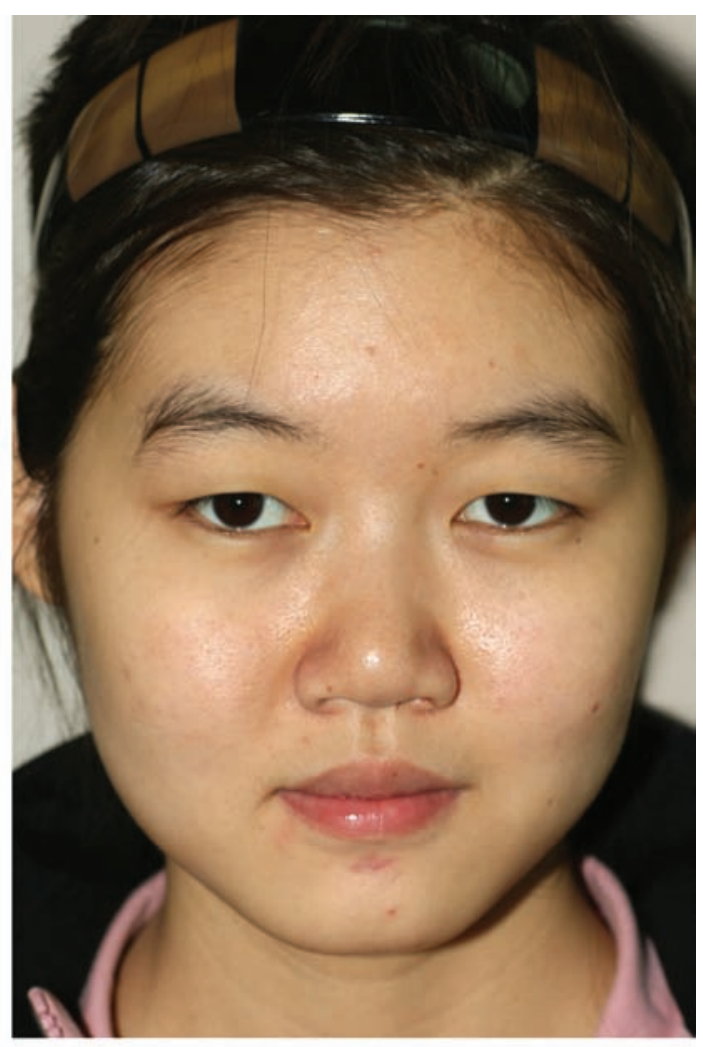

F2

Figure 5) Examples of patients with Asian roots - Northern Asian (F1): white or mildly tanned skin, mildly coarse features; Central Asian (F2): medium tanned skin, moderately coarse features; Southern Asian (F3): medium to dark brown skin, coarse features 


\section{REFERENCES}

1. Fitzpatrick TB. The validity and practicality of sun-reactive skin types 1 through V1. Arch Dermatol 1988;124:869-71.

2. Brody H. Chemical peeling. St-Louis: Mosby 1992;35-41.

3. Monheit G. Advances in chemical peeling. Facial Plast Surg Clin 1994;2:5-9.

4. McCollough G, Langston P. Dermabrasion and Chemical Peeling. A Guide for Facial Plastic Surgeons. New York: THIEME Medical Publishers, 1998

5. Obagi Z. Obagi Symposium Manual, 1992.

6. Fanous N, Hopping S. TCA peel course, Annual Meeting of the American Academy of Cosmetic Surgery, Los Angeles, January 10 to 12,1995 .

7. Fanous N. TCA for Asians. Facial Plast Surg Clinics 1996;4:1195-200.

8. Fanous N, Prinja N, Sawaf M. Laser resurfacing of the neck. Aesth Plast Surg 1998;22:159-65.

9. Fanous N, Bassas AE, Ghamdi WA. $\mathrm{CO}_{2}$ laser resurfacing of the neck and face: 10 golden rules for predicting results and preventing complications. Facial Plast Surg Clin 2000;8:405-13.
10. Fanous N. A new patient classification for laser resurfacing and peels: Predicting responses, risks and results. Aest Plast Surg 2002;26:99-104.

11. McCurdy JA, Lam SM. Cosmetic Surgery of the Asian Face. New York: THIEME Medical Publishers, 2005:253-4

12. Côté V, Fanous N. The new "genetico-racial" skin classification: Maximizing the safety of skin treatments for Asians. Facial Plast Surg Clin, 2009.

13. Darwin C. The Origin of Species. London: John Murray, 1859.

14. Friedrichs HF. Neuer untersuchen zeitschrift fur anatomie und entwicklungsgeschchichte. Schodel und Unterkiefer: von Piltdown, 1932.

15. Wolpoff M, Caspari R. Race and human evolution. New York: Simon and Schuster, 1997.

16. Blumenbach JF. De generis humani varietate nativa, 1775.

17. Dawkins R. The Greatest Show on Earth: The Evidence for Evolution. New York: Free Press (Simon \& Schuter), 2009. 